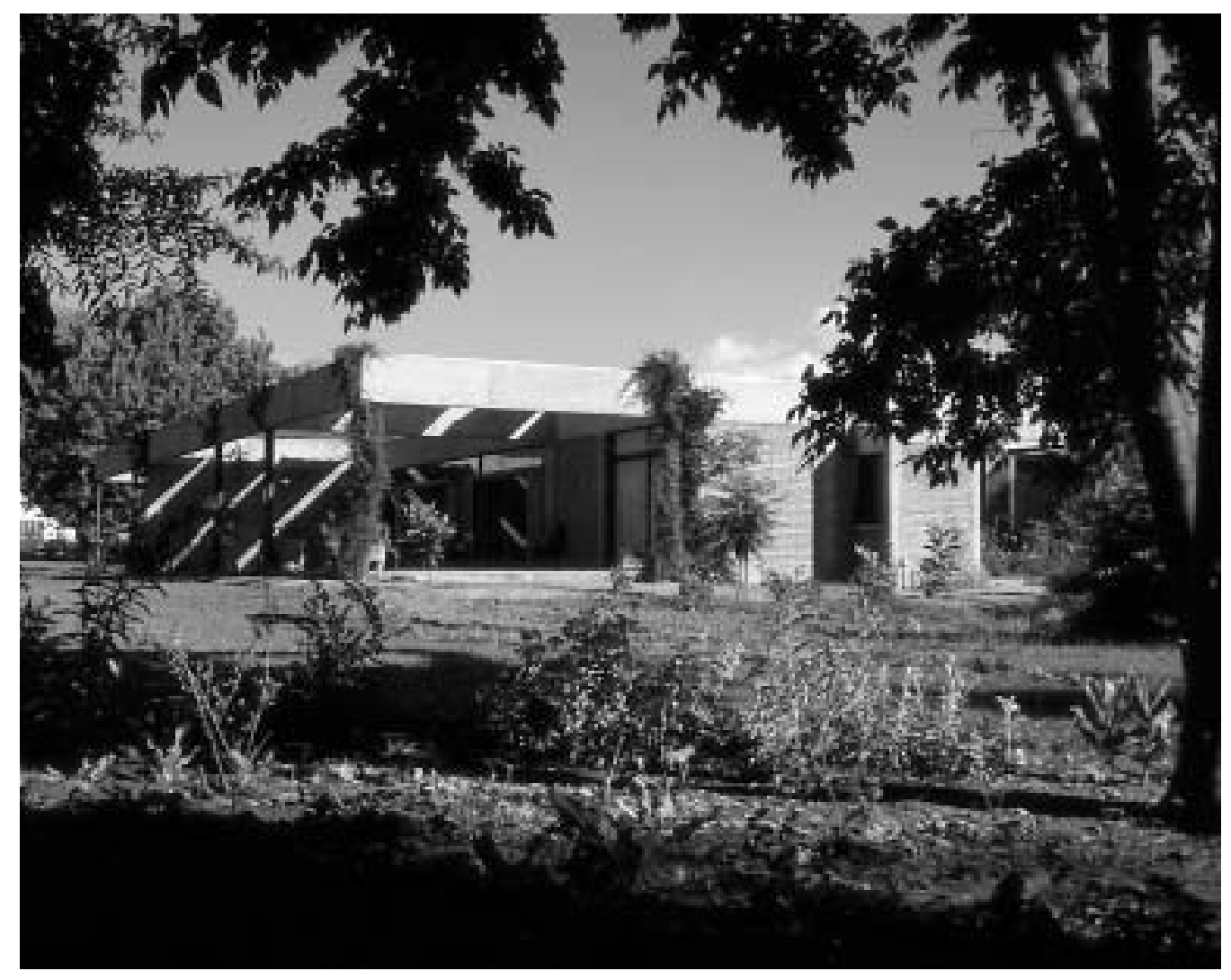

Sebastián Hernández S

Arquitecto colaborador Ignacio Corvalán $\mathrm{R}$.

Mandante

Teresa Gazitúa C. y Francisco Und urraga

Cálculo estructural

Gastón Maltés

Construcción

Raúl Díaz

Materialidad principal

Alb añilería reforzada

Superficie terreno

$5.000 \mathrm{~m}^{2}$

Superficie construid

$238 \mathrm{~m}^{2}\left(275 \mathrm{~m}^{2}\right)$

Fecha proyecto

1998

Fecha construcción

1998-1999

\section{Casa en Pirque}

El sitio de esta casa es el resultado de subdivisión en parcelas de $5.000 \mathrm{~m}^{2}$, la mínima superficie permitida en zonas agrícolas de un parque de $20.000 \mathrm{~m}^{2}$ que se había plantado casi 100 años antes para una casa que finalmente nunca se construyó. $\mathrm{El}$ terreno resultante tiene la forma de un rombo apuntando hacia el norte. El camino de acceso corre paralelo al deslinde suroriente del sitio. La mitad sur se encontraba despejada mientras que la norte estaba ocupada por los árboles ya crecidos del parque original.

Se pidió un programa, quizás habitual para una casa de $250 \mathrm{~m}^{2}$, con algunas particularidades. Normalmente vivirían aquí sólo tres personas, pero era necesario poder recibir un número importante de visitas y alojados los fines de semana y los períodos de vacaciones. Además se debía contar con un taller, relativamente grande $\left(50 \mathrm{~m}^{2}\right)$, con un patio exterior propio que sería el lugar de trabajo permanente para uno de los ocupantes de la casa.

Las dimensiones del terreno y lo restringido del presupuesto frente a los requerimientos exigidos, sugerían un proyecto modesto en su construcción, pero generoso en sus dimensiones. Que diera lugar a la hospitalidad que daría sentido a la casa y organizara el terreno entero.
Considerando el presupuesto disponible, los clientes manifestaron desde un principio su predilección por el ladrillo visto. El ladrillo, al reforzarse con cadenas y pilares de hormigón armado, adquiere una expresión que es característica de la construcción en Santiago. Se propuso dar forma a la casa a partir de la albañilería reforzada, aprovechando sus elementos básicos: muros, pilares, vigas y cadenas. Se dejó la obra gruesa vista, levantando una especie de ruina instantánea. Para los techos se optó por vigas metálicas que sostienen una cubierta de acero galvanizado y cielos falsos de volcanita pintados de blanco. Estos cielos, junto con algunos muros, también pintados de blanco, permiten aliviar la presencia permanente de la obra gruesa.

Para lograr dimensiones más amplias en la casa se privilegiaron ciertos recintos. El taller, el estar y el comedor tienen medidas holgadas frente a otros, como los baños o los dormitorios, que se llevaron a sus dimensiones mínimas. Con esta misma intención se proyectaron recintos semiexteriores, de manera que cada recinto interior de la casa corresponde a uno exterior más o menos equivalente, que lo amplía perceptualmente y complementa su uso. Los recintos cubiertos, los patios y terrazas abiertas, toman su lugar dentro 

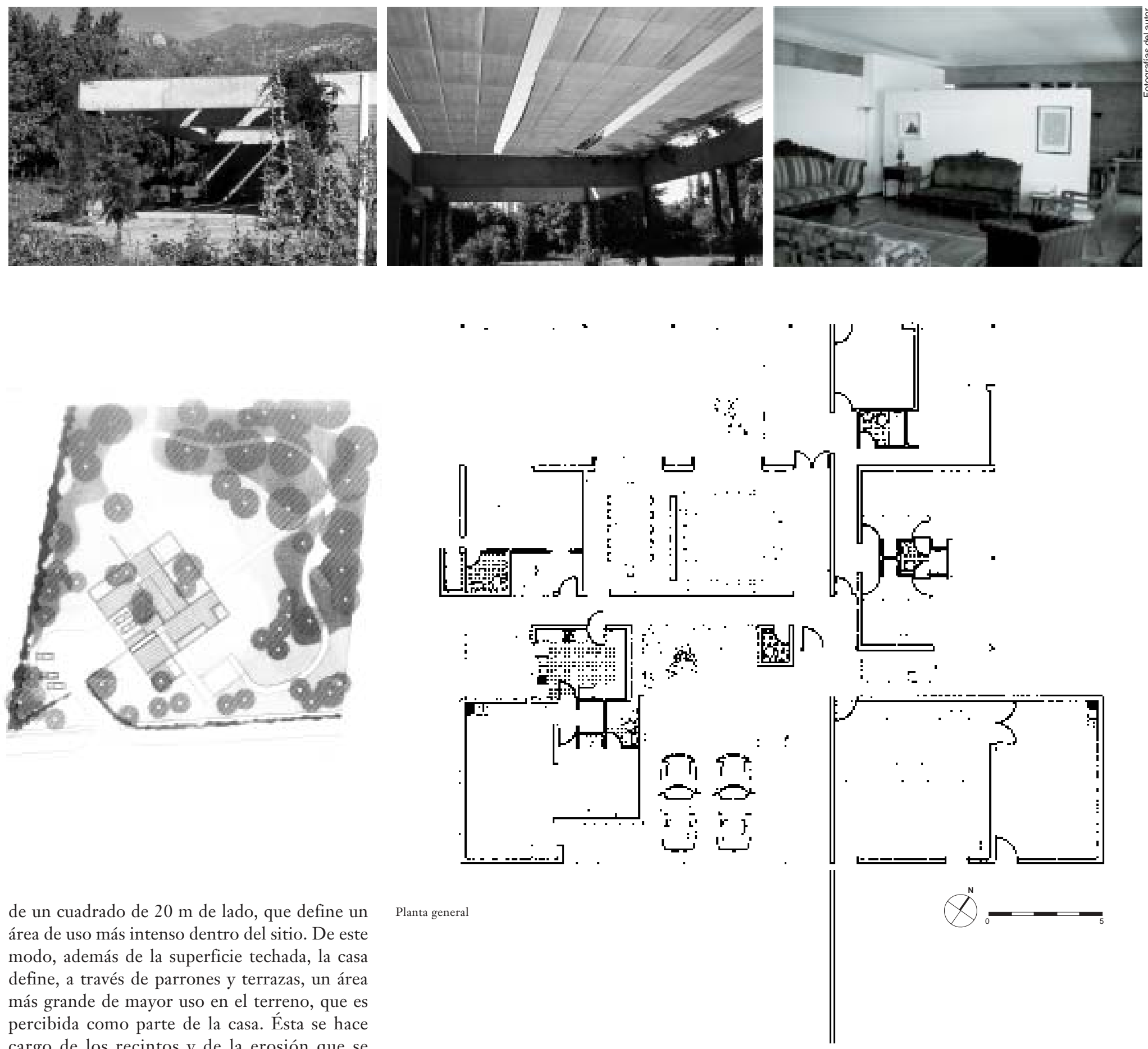

de un cuadrado de $20 \mathrm{~m}$ de lado, que define un área de uso más intenso dentro del sitio. De este modo, además de la superficie techada, la casa define, a través de parrones y terrazas, un área más grande de mayor uso en el terreno, que es percibida como parte de la casa. Ésta se hace cargo de los recintos y de la erosión que se produce alrededor de ellos.

Este cuadrado que define la casa se ubica en la mitad sur del sitio y encuentra su posición a partir de las diagonales del sitio. Estos dos ejes perpendiculares definen cuatro áreas para la casa y para el terreno. Hacia el poniente se ubican el área de servicio y el patio de acceso, hacia el sur el taller y su patio, hacia el oriente los dormitorios de alojados, y hacia el norponiente el dormitorio principal, el comedor y el estar.

Se propone entonces una construcción con cuatro fachadas equivalentes, definida por muros de distintos largos y alturas que reciben sombra de techos, parrones y toldos sostenidos por una vigacadena que la rodea en todo su contorno.

Raúl Hernández Valenzuela

Arquitecto, Pontificia Universidad Católica de Chile,1966. Se dedica al ejercicio libre de la profesión.

Sebastián Hernández Silva

Arquitecto, Pontificia Universidad Católica de Chile, 1997. Trabaja con el arquitecto Teodoro Fernández Larrañaga desde 1994.

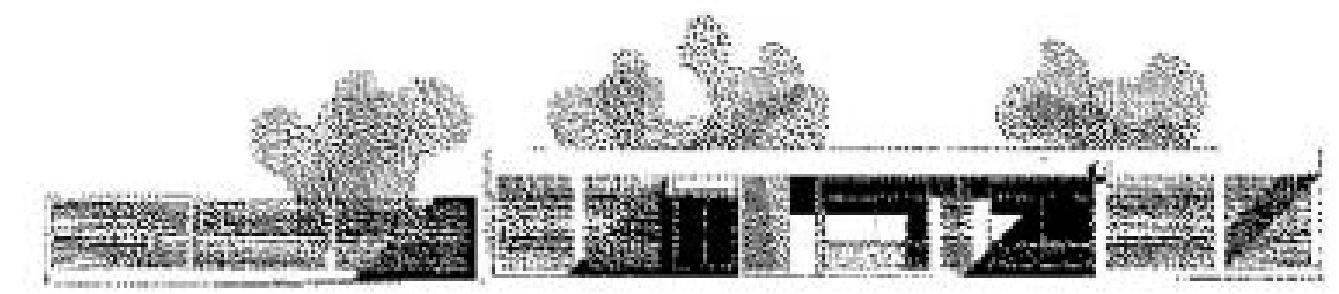

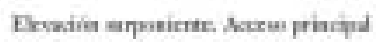

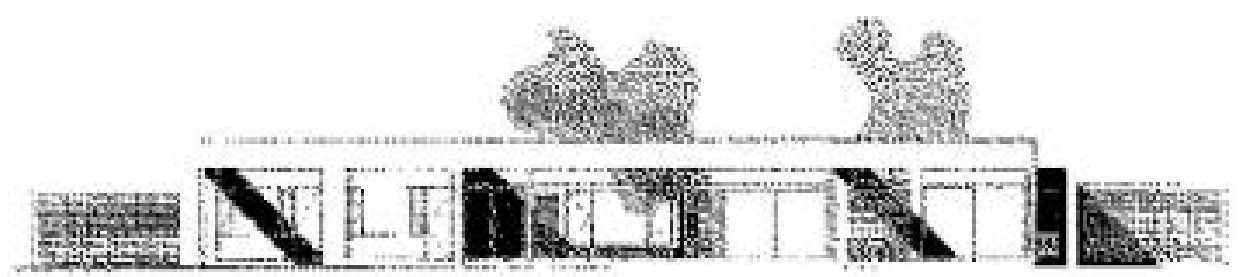

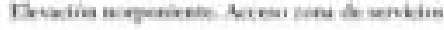

